\title{
Pleiocarpon gen. nov. and a new species of llyonectria causing basal rot of Strelitzia reginae in Italy
}

\author{
Dalia Aiello', Giancarlo Polizzi'1, Pedro W. Crous ${ }^{2,3,4}$, and Lorenzo Lombard ${ }^{2}$
}

1'Dipartimento di Agricoltura, Alimentazione e Ambiente, sezione Patologia Vegetale, University of Catania, Via S. Sofia 100, 95123 Catania, Italy; corresponding author e-mail: dalia.aiello@live.it

${ }^{2}$ Westerdijk Fungal Biodiversity Institute, Uppsalalaan 8, 3584CT Utrecht, The Netherlands

${ }^{3}$ Microbiology, Department of Biology, Utrecht University, Padualaan 8, 3584 CT Utrecht, The Netherlands

${ }^{4}$ Department of Microbiology and Plant Pathology, Tree Protection Co-operative Programme, Forestry and Agricultural Biotechnology Institute, University of Pretoria, Pretoria 0002, South Africa

\begin{abstract}
During 2015, a new basal rot disease was observed on potted plants of Strelitzia reginae in an ornamental nursery located in eastern Sicily. Isolations from symptomatic parts of these diseased plants consistently yielded cylindrocarpon-like isolates. Multigene analyses of the partial gene regions of $28 \mathrm{~S}$ large subunit nrDNA, $\beta$-tubulin, histone $\mathrm{H} 3$, translation elongation factor 1-alpha, internal transcribed spacer region and intervening 5.8S nrRNA gene, and RNA polymerase II second largest subunit genes, supported by morphological characters supported the recognition of a new genus, Pleiocarpon based on $P$. strelitziae sp. nov., and a new llyonectria species, described here as $I$. strelitziae sp. nov. The pathogenicity of both $I$. strelitziae and $P$. strelitziae were confirmed on young plants cultivated under controlled conditions in a growth chamber. Both cylindrocarpon-like fungi were pathogenic to $S$. reginae and reproduced symptoms similar to those observed in the nursery. Of the two species, $P$. strelitziae was more aggressive than $I$. strelitziae, resulting in the death of all inoculated plants.
\end{abstract}

\author{
Key words: \\ Nectriaceae \\ multigene phylogeny \\ pathogenicity \\ taxonomy
}

Article info: Submitted: 16 December 2017; Accepted: 15 March 2017; Published: 5 April 2017.

\section{INTRODUCTION}

Strelitzia reginae, also well-known as "bird of paradise", is one of the most commercially cultivated species of Strelitzia in the world (Karsten 2009). This species was first introduced into Europe from South Africa in 1770 for its unique flowers, which are characterized by vivid orange and bright purple or blue inflorescens, making it a highly sought-after cut flower crop (Van Jaarsveld 2008, Xaba 2011). This plant is also widely used in landscaping as a focal point for many European gardens (Xaba 2011). However, commercial cultivation of $S$. reginae, as cut flowers or as pot plants, is limited by fungal diseases, which are poorly reported in the literature.

In Hawaii, a Pythium sp. has been reported as causal agent of root rot on $S$. reginae, and a similar disease was reported in Egypt and Florida associated with Rhizoctonia solani and Fusarium spp. (Raabe et al. 1981, Alfenas et al. 1984, Hilal \& Helmy 1998). In Italy, the most commonly reported fungal diseases of $S$. reginae are root and foot rot caused by Phytophthora nicotianae (Frisullo et al. 1987, Luongo et al. 2010), wilting associated with root rot caused by "Cylindrocarpon" destructans (Grasso \& Cutuli 1972) and Armillaria mellea (Davino 1984), and southern blight caused by Sclerotium rolfsii (Polizzi et al. 2007).

During 2015, a new basal stem rot was detected on approximately $20 \%$ of 20000 potted S. reginae plants in a commercial nursery in Carrubba, Riposto (Catania province, eastern Sicily, Italy). The diseased plants displayed a dry rot of the basal stem which resulted in the detachment of the roots from the stem. In addition, symptoms of general wilting and rot of internal foliage were observed on the affected plants. The aims of this study were, therefore, to identify the pathogen(s) associated with the disease via morphological and molecular characterization, and to verify the pathogenicity of the organism(s) associated with these disease symptoms.

\section{MATERIALS AND METHODS}

\section{Field survey and isolation}

During 2015, a survey undertaken in an ornamental nursery in eastern Sicily led to the discovery of Strelizia reginae plants displaying symptoms of dry basal stem rot (Fig. 1). Some affected plants were randomly selected and brought to the laboratory for further analyses. The symptomatic stem tissues were surface-sterilized with $1.2 \%(\mathrm{v} / \mathrm{v})$ sodium hypochlorite for $2 \mathrm{~min}$, rinsed three times in sterile distilled water and dried on sterile absorbent paper. Isolations were done by transferring fragments of symptomatic and the bordering healthy plant tissue onto potato dextrose agar (PDA, Oxoid ${ }^{\mathrm{TM}}$ Lda, UK) plates (amended with streptomycin sulphate at 100 ppm) and Phytophthora selective medium PARPH (Jeffers

\section{2017 International Mycological Association}

You are free to share - to copy, distribute and transmit the work, under the following conditions:

Attribution: $\quad$ You must attribute the work in the manner specified by the author or licensor (but not in any way that suggests that they endorse you or your use of the work).

Non-commercial: $\quad$ You may not use this work for commercial purposes.

No derivative works: You may not alter, transform, or build upon this work.

For any reuse or distribution, you must make clear to others the license terms of this work, which can be found at http://creativecommons.org/licenses/by-nc-nd/3.0/legalcode. Any of the above conditions can be waived if you get permission from the copyright holder. Nothing in this license impairs or restricts the author's moral rights. 


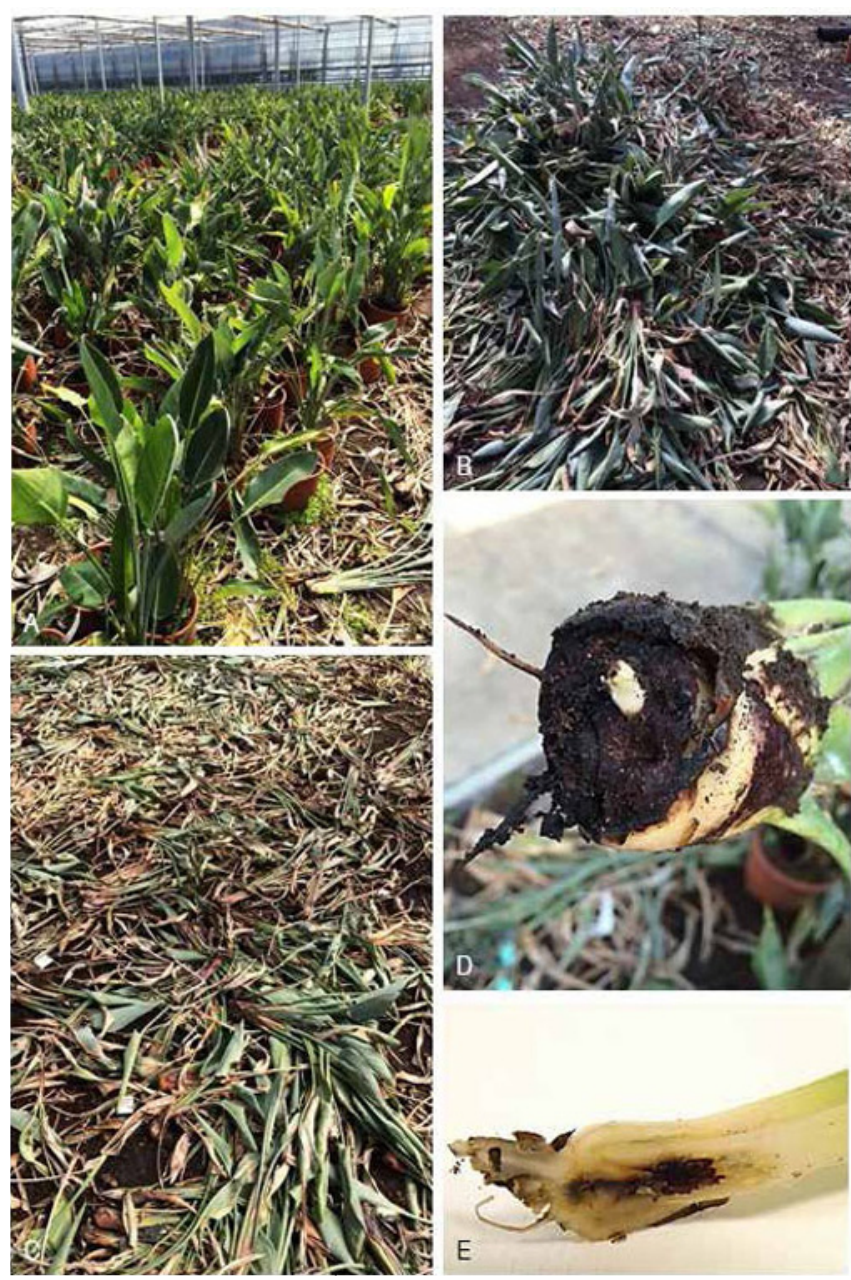

Fig. 1. Dry basal rot symptoms of Strelitzia reginae observed in the nursery. A-C. Wilting and dying S. reginae plants. D. Dry basal stem rot. E. Rot of internal leaf.

\& Martin 1986). The plates were incubated at $25{ }^{\circ} \mathrm{C}$ and examined daily for $1 \mathrm{wk}$. From these primary isolations, single-conidial isolates were derived and maintained on PDA slants for further study.

\section{DNA isolation, sequencing and phylogenetic analyses}

Total genomic DNA was extracted from 7-d-old fungal strains grown on PDA at room temperature $\left(20-24^{\circ} \mathrm{C}\right)$ using the Wizard $\AA$ Genomic DNAPurification Kit (Promega Corporation, Madison, WI) according to the manufacturer's protocol. Six genomic gene regions were targeted for amplification and sequencing using the primer pairs and protocols described by Lombard et al. (2015): 28 S large subunit (LSU) nrDNA, internal transcribed spacer regions and intervening $5.8 \mathrm{~S}$ nrRNA (ITS), translation elongation factor 1-alpha (tef1), histone $\mathrm{H} 3$ (his3), $\beta$-tubulin (tub2), and the RNA polymerase II second largest subunit (rpb2) gene regions.

Amplicons were sequenced in both directions using the same primers used for amplification and the BigDye ${ }^{\circledR}$ Terminator Cycle Sequencing Kit v. 3.1 (Applied Biosystems Life Technologies, Carlsbad, CA) following the protocol provided by the manufacturer. Sequences were determined on an Applied Biosystems 3730 DNA Analyzer (Life Technologies, Carlsbad,
CA). The generated sequences were analysed and consensus sequences were determined using Seqman (DNAStar, Madison, WI). All sequences were manually corrected and the arrangement of nucleotides in ambiguous positions corrected by comparisons of the sequences generated from both the forward and reverse primers. In addition to the sequences generated in this study, other sequences of closely related Nectriaceae were obtained from NCBl's GenBank nucleotide database and added to the sequence datasets generated in this study. The sequences for each locus were aligned using MAFFT v. 7 (Katoh \& Standley 2013). The alignments were manually checked using MEGA v. 7 (Kumar et al. 2015) and improved where necessary. Novel sequences were lodged in GenBank (Table 1), and the alignments and phylogenetic trees in TreeBASE (S20598). Congruency of the six loci was tested using the $70 \%$ reciprocal bootstrap criterion (Mason-Gamer \& Kellogg 1996) following the protocol of Lombard et al. (2015) for each locus.

Phylogenetic analyses were based on Bayesian inference (BI), Maximum Likelihood (ML), and Maximum Parsimony (MP). For both $\mathrm{BI}$ and $\mathrm{ML}$, the evolutionary model for each partition was determined using MrModeltest (Nylander 2004) and incorporated into the analyses. For the $\mathrm{BI}$ analysis, MrBayes v. 3.1.1 (Ronquist \& Huelsenbeck 2003) was used to generate phylogenetic trees under the optimal model per partition. A Markov Chain Monte Carlo (MCMC) algorithm of four chains was started in parallel from a random tree topology with the heating parameter set to 0.3. The MCMC analysis lasted until the average standard deviation of split frequencies decreased below 0.01 with trees saved each 1000 generations. The first $25 \%$ of saved trees were discarded as "burn-in" and posterior probabilities determined from the remaining trees.

The ML analysis was made with RAxML (randomized axelerated [sic] maximum likelihood for high performance computing; Stamatakis 2014) through the CIPRES website (http://www.phylo.org) to obtain a second measure of branch support. The robustness of the analysis was evaluated by bootstrap support (BS) analysis with the bootstrap replicates automatically determined by the software.

The MP analysis was carried out with PAUP (Phylogenetic Analysis Using Parsimony, v. 4.0b10; Swofford 2003) with phylogenetic relationships estimated by heuristic searches with 1000 random sequence-additions. Tree bisectionreconnection was implemented, with the branch swapping option set on "best tree" only. All characters were weighted equally and alignment gaps were treated as "fifth state". Measures calculated for parsimony included tree length (TL), consistency index $(\mathrm{Cl})$, retention index $(\mathrm{RI})$ and rescaled consistency index (RC). The bootstrap support analysis was based on 1000 replications.

\section{Taxonomy}

Axenic cultures were grown on synthetic nutrient-poor agar (SNA; Nirenburg 1981) amended with $1-\mathrm{cm}^{2}$ sterile filter paper and carnation leaf pieces, and on PDA as described by Cabral et al. (2012a). Gross morphological characteristics were studied by mounting the fungal structures in $85 \%$ lactic acid and 30 measurements were made for all taxonomically informative characters at $\times 1000$ magnification using a 
Table 1. Strains included in the phylogenetic analyses.

\begin{tabular}{|c|c|c|c|c|c|c|c|c|c|}
\hline \multirow[b]{2}{*}{ Species } & \multirow[b]{2}{*}{ Isolate $\mathrm{nr}^{1}{ }^{1}$} & \multirow[b]{2}{*}{ Substrate } & \multirow[b]{2}{*}{ Locality } & \multicolumn{6}{|c|}{ GenBank Accession no. ${ }^{2}$} \\
\hline & & & & ITS & LSU & his3 & $r p b 2$ & tef1 & tub2 \\
\hline Campylocarpon fasciculare & CBS 112613; CРC 3970 & Vitis vinifera & South Africa & AY677301 & HM364313 & - & - & JF735691 & AY677221 \\
\hline C. pseudofasciculare & CBS 112679; СРС 5472 & V. vinifera & South Africa & AY677306 & НМ364314 & - & - & JF735692 & AY677214 \\
\hline \multirow[t]{2}{*}{ Cinnamomeonectria cinnamomea } & CBS 136783; PC 1222 & Bark & Brazil & KJ021998 & KJ022049 & - & - & KJ022376 & KJ022344 \\
\hline & IMI 325248; G.J.S. 86-117 & Bark of living liana & French Guiana & KJ022010 & KJ022072 & - & - & KJ022393 & KJ022341 \\
\hline \multirow[t]{2}{*}{ Cylindrocarpostylus gregarius } & CBS 101072 & Hylurgops palliatus & Germany & KM231747 & JQ666084 & - & - & KM231870 & KM232005 \\
\hline & CBS 101073 & Pinus sylvestris & Germany & KM231748 & JQ666083 & - & - & KM231871 & KM232006 \\
\hline \multirow[t]{2}{*}{ Cylindrodendrum album } & СBS 301.83; АТCC 46842; IMI 255534 & Fucus distichus & Canada & KM231764 & KM231626 & - & - & KM231889 & KM232021 \\
\hline & CBS 110655 & Soil & The Netherlands & KM231765 & KM231627 & - & - & KM231890 & KM232022 \\
\hline Dactylonectria alcacerensis & CBS 129087 & V. vinifera & Portugal & JF735333 & KM231629 & - & - & JF735819 & AM419111 \\
\hline D. estremocensis & CBS 129085 & V. vinifera & Portugal & JF735320 & KM231630 & - & - & JF735806 & JF735448 \\
\hline D. macrodidyma & CВS 112615; СРС 3976 & V. vinifera & South Africa & AY677290 & KM515900 & - & - & JF735836 & AY677233 \\
\hline D. torresensis & CBS 129086 & V. vinifera & Portugal & JF735362 & KM231631 & - & - & JF735870 & JF735492 \\
\hline Ilyonectria capensis & CBS 132815; CPC 20695 & Protea sp. & South Africa & $J X 231151$ & KM515908 & - & - & JX231119 & JX231103 \\
\hline I. destructans & CBS 264.65 & Cyclamen persicum & Sweden & AY677273 & KM515927 & - & - & JF735695 & AY677256 \\
\hline I. leucospermi & CBS 132809; CPC 20701 & Leucospermum sp. & South Africa & $J X 231161$ & KM515917 & - & - & JX231129 & $J X 231113$ \\
\hline I. liriodendri & CBS 117527 & V. vinifera & Portugal & DQ178165 & KM515922 & - & - & JF735698 & DQ178172 \\
\hline I. mors-panacis & CBS 306.35 & Panax quinquefolium & Canada & JF735288 & - & - & - & JF735746 & JF735414 \\
\hline I. palmarum & CBS 135753 & Howea forsteriana & Italy & HF937432 & - & - & - & HF922615 & HF922609 \\
\hline \multirow[t]{10}{*}{ I. strelitziae } & CBS 142253; ST6 & Strelitzia reginae & Italy & KY304649 & KY304674 & KY304621 & KY304701 & KY304727 & KY304755 \\
\hline & CBS 142254; ST8 & S. reginae & Italy & KY304651 & KY304676 & KY304623 & КУ304703 & KY304729 & KY304757 \\
\hline & ST7 & S. reginae & Italy & KY304650 & KY304675 & KY304622 & KY304702 & KY304728 & KY304756 \\
\hline & ST9 & S. reginae & Italy & KY304652 & KY304677 & КY304624 & КY304704 & КY304730 & КY304758 \\
\hline & ST14 & S. reginae & Italy & KY304657 & KY304682 & KY304629 & - & KY304735 & КY304763 \\
\hline & ST15 & S. reginae & Italy & KY304658 & KY304683 & KY304630 & KY304708 & KY304736 & KY304764 \\
\hline & ST25 & S. reginae & Italy & KY304668 & KY304693 & KY304640 & KY304718 & KY304746 & KY304774 \\
\hline & ST26 & S. reginae & Italy & KY304669 & KY304694 & KY304641 & КУ304719 & КY304747 & KY304775 \\
\hline & ST27 & S. reginae & Italy & KY304670 & KY304695 & KY304642 & KY304720 & KY304748 & КY304776 \\
\hline & ST28 & S. reginae & Italy & KY304671 & KY304696 & KY304643 & KY304721 & KY304749 & KY304777 \\
\hline Macronectria jungneri & CBS 136792 & Bark & Brazil & KJ021997 & KJ022048 & - & - & KJ022375 & KJ022313 \\
\hline M. magna & CBS 213.59 & Theobroma cacao & Guatemala & KJ021981 & KJ022034 & - & - & KJ022361 & KJ022300 \\
\hline M. venezuelana & CBS 136786; G.J.S. 09-1343 & Wood & Venezuela & KJ021986 & KJ022037 & - & - & KJ022365 & KJ022303 \\
\hline Neonectria candida & CBS 151.29; IMI 113893 & Malus sylvestris & England & JF735313 & HM042436 & - & - & JF735791 & JF735438 \\
\hline N. ditissima & CBS 100316 & M. domestica & Ireland & KM515890 & KM515935 & - & - & KM515944 & DQ789858 \\
\hline N. lugdunensis & CBS 125185; DAOM 235831 & Populus fremontii & USA & KM231762 & KM231625 & - & - & KM231887 & KM232019 \\
\hline
\end{tabular}


Table 1. (Continued).

\begin{tabular}{|c|c|c|c|c|c|c|c|c|c|}
\hline \multirow[b]{2}{*}{ Species } & \multirow[b]{2}{*}{ 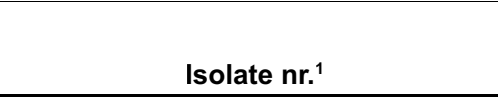 } & \multirow[b]{2}{*}{ Substrate } & \multirow[b]{2}{*}{ Locality } & \multicolumn{6}{|c|}{ GenBank Accession no. ${ }^{2}$} \\
\hline & & & & ITS & LSU & his3 & rpb2 & tef1 & tub2 \\
\hline N. neomacrospora & CBS 324.61 & Abies concolor & The Netherlands & JF735312 & HM364318 & - & - & HM364335 & DQ789875 \\
\hline \multirow[t]{17}{*}{ Pleiocarpon strelitziae } & CBS 142251; ST1; CPC 27628 & S. reginae & Italy & KY304644 & KY304672 & KY304616 & KY304697 & KY304722 & KY304750 \\
\hline & CBS 142252; ST20 & S. reginae & Italy & KY304663 & KY304688 & KY304635 & KY304713 & KY304741 & КY304769 \\
\hline & CPC 27629 & S. reginae & Italy & KY304645 & - & KY304617 & KY304698 & KY304723 & KY304751 \\
\hline & ST3 & S. reginae & Italy & KY304646 & - & KY304618 & - & KY304724 & KY304752 \\
\hline & ST4 & S. reginae & Italy & KY304647 & - & KY304619 & KY304699 & KY304725 & KY304753 \\
\hline & ST5 & S. reginae & Italy & KY304648 & KY304673 & KY304620 & KY304700 & KY304726 & КY304754 \\
\hline & ST10 & S. reginae & Italy & KY304653 & KY304678 & КY304625 & КY304705 & КY304731 & КY304759 \\
\hline & ST11 & S. reginae & Italy & KY304654 & KY304679 & KY304626 & KY304706 & KY304732 & KY304760 \\
\hline & ST12 & S. reginae & Italy & KY304655 & KY304680 & KY304627 & KY304707 & KY304733 & KY304761 \\
\hline & ST13 & S. reginae & Italy & KY304656 & KY304681 & KY304628 & - & KY304734 & KY304762 \\
\hline & ST17 & S. reginae & Italy & KY304660 & KY304685 & КY304632 & KY304710 & KY304738 & КY304766 \\
\hline & ST18 & S. reginae & Italy & KY304661 & KY304686 & KY304633 & KY304711 & KY304739 & KY304767 \\
\hline & ST19 & S. reginae & Italy & KY304662 & KY304687 & KY304634 & KY304712 & KY304740 & KY304768 \\
\hline & ST21 & S. reginae & Italy & KY304664 & KY304689 & КY304636 & КY304714 & KY304742 & КY304770 \\
\hline & ST22 & S. reginae & Italy & KY304665 & KY304690 & KY304637 & KY304715 & KY304743 & KY304771 \\
\hline & ST23 & S. reginae & Italy & KY304666 & KY304691 & KY304638 & KY304716 & KY304744 & KY304772 \\
\hline & ST24 & S. reginae & Italy & KY304667 & KY304692 & КY304639 & KY304717 & KY304745 & КY304773 \\
\hline Rugonectria neobalansae & CBS 125120 & Dead tree & Indonesia & KM231750 & HM364322 & - & - & KM231874 & HM352869 \\
\hline R. rugulosa & CBS 126565 & Dead tree & Venezuela & KM231749 & KM231615 & - & - & KM231873 & KM232007 \\
\hline Thelonectria discophora & CBS 134034; AR 4742 & Tepualia stipularis & Chile & KC153714 & KC121440 & - & - & KC153843 & KC153779 \\
\hline \multirow[t]{2}{*}{ T. olida } & CBS 215.67; ATCC 16548; IMI 116873 & Asparagus officinalis & Germany & KJ021982 & KJ022058 & - & - & - & KM232024 \\
\hline & CBS 142255 & S. reginae & Italy & KY304659 & KY304684 & KY304631 & KY304709 & KY304737 & KY304765 \\
\hline T. rubi & CBS 113.12; IMI 113918 & Rubus idaeus & & KC153718 & KC121444 & - & - & KC153847 & KC153783 \\
\hline T. trachosa & CBS 112467; IMI 352560 & Bark of conifer & Scotland & AY677297 & HM364312 & - & - & KM231896 & AY677258 \\
\hline T. veuillotiana & CBS 132341; AR 1751 & Eucalyptus sp. & Azores & JQ403305 & JQ403345 & - & - & JQ394734 & JQ394698 \\
\hline \multirow[t]{2}{*}{ Tumenectria laetidisca } & CBS 100284 & Bamboo & Japan & KJ022017 & KJ022066 & - & - & KJ022400 & KJ022336 \\
\hline & CBS 101909 & Bamboo & Jamaica & KJ022018 & KJ022067 & - & - & KJ022401 & KJ022337 \\
\hline Xenogliocladiopsis cypellocarpa & CBS 133814; CPC 19417 & $\begin{array}{l}\text { Eucalyptus } \\
\text { cypellocarpa }\end{array}$ & Australia & KM231760 & KM231623 & - & - & KM231885 & KM232017 \\
\hline
\end{tabular}

'AR: Amy Y. Rossman working collection; ATCC: American Type Culture Collection, Virginia, USA; CBS: Centraalbureau voor Schimmelcultures, Utrecht, The Netherlands; CPC: Pedro Crous working

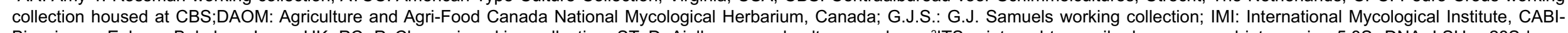

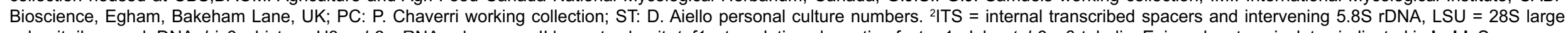
subunit ribosomal rDNA, his $3=$ histone $\mathrm{H} 3$, rpb2 $=$ RNA polymerase II largest subunit, tef1 = translation elongation factor 1 -alpha, tub2 = $\beta$-tubulin. Epi- and ex-type isolates indicated in bold. Sequences generated in this study indicated in italics. 
Plan-Apochromat $\times$ 100/1.4 oil immersion lens (Carl Zeiss, Germany) mounted on a Zeiss Axioscope 2 microscope, with differential interference contrast (DIC) illumination. The $95 \%$ confidence levels were determined for the conidial measurements with extremes given in parentheses. For all other fungal structures measured, only the extremes are provided. Colony colour was assessed using 7-d-old cultures on PDA incubated at room temperature and the colour charts of Rayner (1970). All descriptions, illustrations and nomenclatural data were deposited in MycoBank (Crous et al. 2004). Optimal and cardinal growth temperatures were determined by inoculating $90 \mathrm{~mm}$ diam PDA plates with a 4 $\mathrm{mm}$ diam plug cut from the edge of an actively growing colony. Each isolate was incubated at 4, 10, 15, 20, 25, 30, and 35 ${ }^{\circ} \mathrm{C}$ with three replicate plates per strain at each temperature. Colony diameter of each isolate was determined after $1 \mathrm{wk}$ by measuring the orthogonal directions.

\section{Pathogenicity}

Two representative isolates for each phylogenetically resolved species (CBS 142251-142254) were selected for pathogenicity tests on 6-mo-old Strelizia reginae plants. Twenty plants were used for each isolate and the same number of plants was used as control. All plants were removed from their original planting substrate, rinsed with water, dipped for 1 min in a $0.3 \%(\mathrm{v} / \mathrm{v})$ mixed solution of $5 \%(\mathrm{v} / \mathrm{v})$ peracetic acid and $20 \%(\mathrm{v} / \mathrm{v})$ hydrogen peroxide (JetFive, Certis Europe), and then rinsed twice with sterile distilled water. Each plant was inoculated with a $4 \mathrm{~mm}$ mycelium plug obtained from the margin of an actively growing 14-d-old culture grown on PDA. Each plug was applied to a wound made at the base of the stem using a $4 \mathrm{~mm}$ diam cork borer as previously reported (Aiello et al. 2014, 2015). Control plants were treated similarly but inoculated with sterile PDA plugs. After inoculation, each plant was wrapped with Parafilm around the inoculation point to prevent desiccation and transplanted into pots containing sterilized growth substrate. All plants were covered with a plastic bag, and maintained in a growth chamber at $25^{\circ} \mathrm{C}$ under a $12 \mathrm{~h}$ fluorescent light/dark regimen. All plants were irrigated 2-4 times every week and fertilised every $30 \mathrm{~d}$ with 2 $\mathrm{g} /$ pot of complex NPK fertilizer Nitrophoska® special (BASF). Plants were evaluated for disease symptoms after 2 and 4 mo.

\section{RESULTS}

\section{Field survey and isolation}

During the survey, dry basal stem rot symptoms were observed on Strelizia reginae in a nursery where these plants are commercially cultivated (Fig. 1). These symptoms were observed on approximately 4000 of 20000 potted 2- to 8 -yr-old potted plants. Isolations from the symptomatic and bordering healthy tissues consistently yielded cylindrocarponlike asexual fungi and no Phytophthora or any other fungi previously reported from $S$. reginae were isolated.

\section{Phylogenetic analyses}

Approximately 325 bases for tub2, 500-550 bases for his3, ITS and tef1, and 850-900 bases for LSU and rpb2 were determined in this study. Due to the limited sequence data available in GenBank for cylindrocarpon-like fungi for the his3 and rpb2 gene regions, both loci could not be included in the phylogenetic inference. The $70 \%$ reciprocal bootstrap tree topologies for the remaining four loci revealed no conflicts and were therefore combined.

The combined alignment of the ITS, LSU, tef1 and tub2 contained 2280 characters from 63 taxa, including Xenogliocladiopsis cypellocarpa (CBS 133814; Lombard et al. 2015) as outgroup. The number of unique site patterns per data partition, including alignment gaps, was 292 from 570 characters for ITS, 139 from 828 characters for LSU, 377 from 577 characters for tef1, and 124 from 305 characters for tub2. MrModeltest determined that all four partitions had dirichlet base frequencies. A GTR $+1+G$ model with inverse gamma-distributed rates was used for ITS, LSU and tef1, while $H K Y+\mid+G$ with inverse gamma-distributed rates was implemented for tub2.

The Bayesian analysis lasted 440000 generations and the consensus tree, with posterior probabilities, was calculated from 662 trees left after 220 trees were discarded as burnin. For the MP analysis 1317 characters were constant, 115 parsimony-uninformative, and 848 parsimony-informative, yielding 216 equally most parsimonious trees $(T L=3566 ; \mathrm{Cl}$ $=0.508 ; \mathrm{RI}=0.848 ; \mathrm{RC}=0.431) . \mathrm{ML}$ analysis resulted in a single best $M L$ tree with $-\operatorname{InL}=-16500.190463$. The best $M L$ tree confirmed the consensus tree topologies obtained from the $\mathrm{BI}$ and MP analyses, and therefore only the best ML tree is presented (Fig. 2).

In the phylogenetic tree (Fig. 2), the majority of the cylindrocarpon-like isolates obtained from Strelizia reginae clustered into two highly-supported clades (both with MP and $\mathrm{ML}$ bootstrap support (BS) of $100 \%$ and posterior probabilities (PP) of 1.0) with a single isolate (CBS 142255) clustering (MP-BS \& ML-BS = $100 \%$; PP = 1.0) with the extype of Thelonectria olida (CBS 215.67). The first group of isolates (including CBS 142253 and CBS 142254) formed a highly-supported clade within the llyonectria clade, closely related but distinct from the ex-type sequence of $I$. palmarum (CBS 135753), thus representing a novel phylogenetic species within the cylindrocarpon-like genus Ilyonectria. The second group of isolates (including CBS 142251 and CBS 142252) formed a highly-supported clade closely related but distinct from the Thelonectria clade, representing a previously unrecognized phylogenetically-supported genus.

\section{Pathogenicity}

After $10 \mathrm{~d}$, both isolates of the species named below as Pleiocarpon strelitziae (CBS 142251 and CBS 142252) induced dry basal stem rot symptoms on Strelizia reginae similar to those observed in the nursery (Fig. 3). As a consequence, after $2 \mathrm{mo}$, all $S$. reginae plants inoculated with $P$. strelitziae died. Both isolates of the species named here as Ilyonectria strelitziae (CBS 142254 and CBS 142253; Fig. 3) also induced symptoms of dry basal stem rot as observed in the nursery after $2 \mathrm{mo}$, but the plants remained alive after 4 mo. All control plants remained healthy throughout the pathogenicity test and none of the test fungi were isolated from them. Re-isolations from the symptomatic plants only yielded the respective inoculated fungi. 


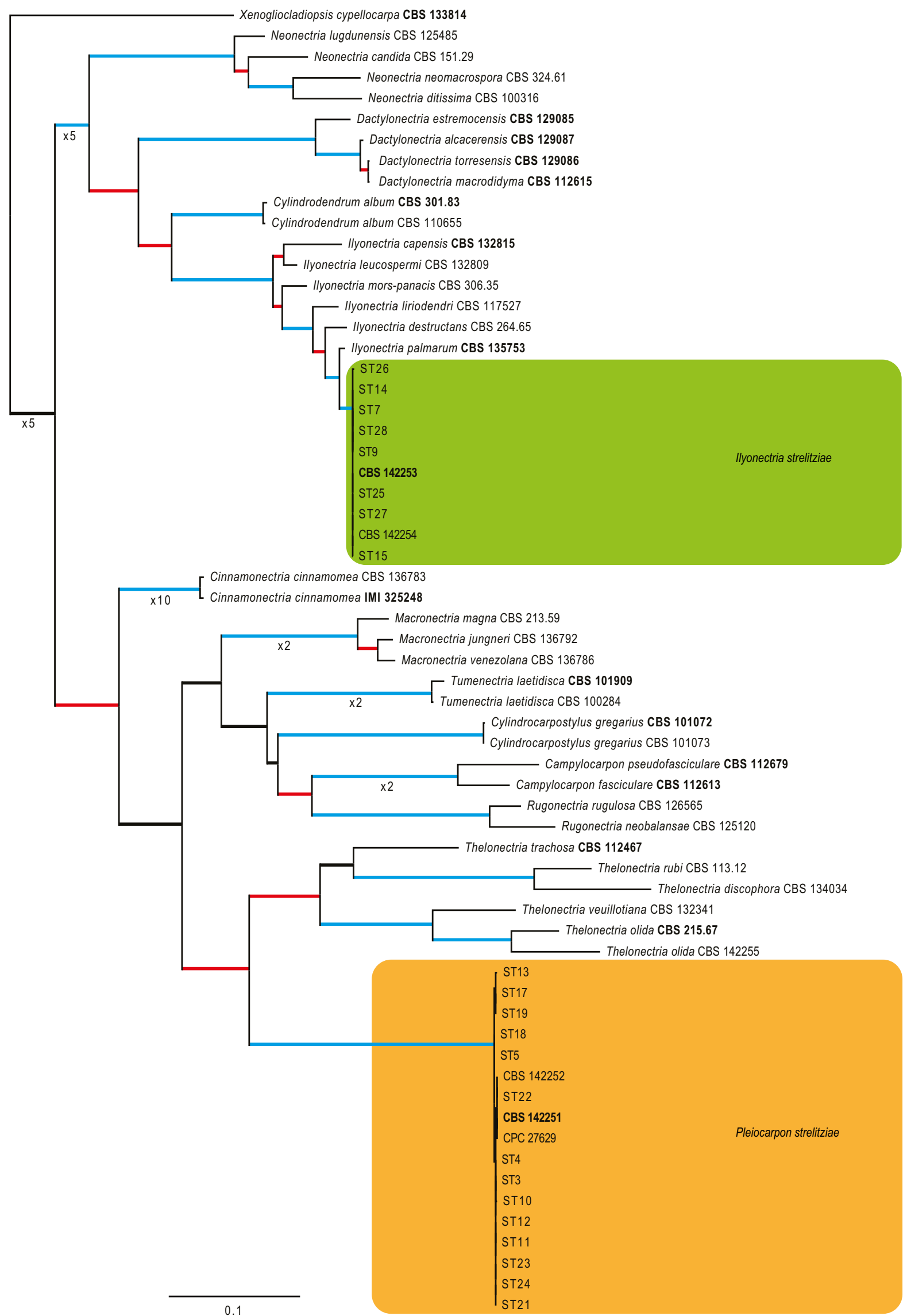

Fig. 2. The ML consensus tree inferred from the combined ITS, LSU, tef1 and tub2 sequence alignments. Thickened branches indicate branches present in the ML, MP and Bayesian consensus trees. Branches with ML-BS \& MP-BS $=100 \%$ and PP $=1.0$ are in blue. Branches with MLBS \& MP-BS $\geq 75 \%$ and PP $\geq 0.95$ are in red. The scale bar indicates 0.1 expected changes per site. The tree is rooted to Xenogliocladiopsis cypellocarpa (CBS 133814). Epi- and ex-type strains are indicated in bold. 


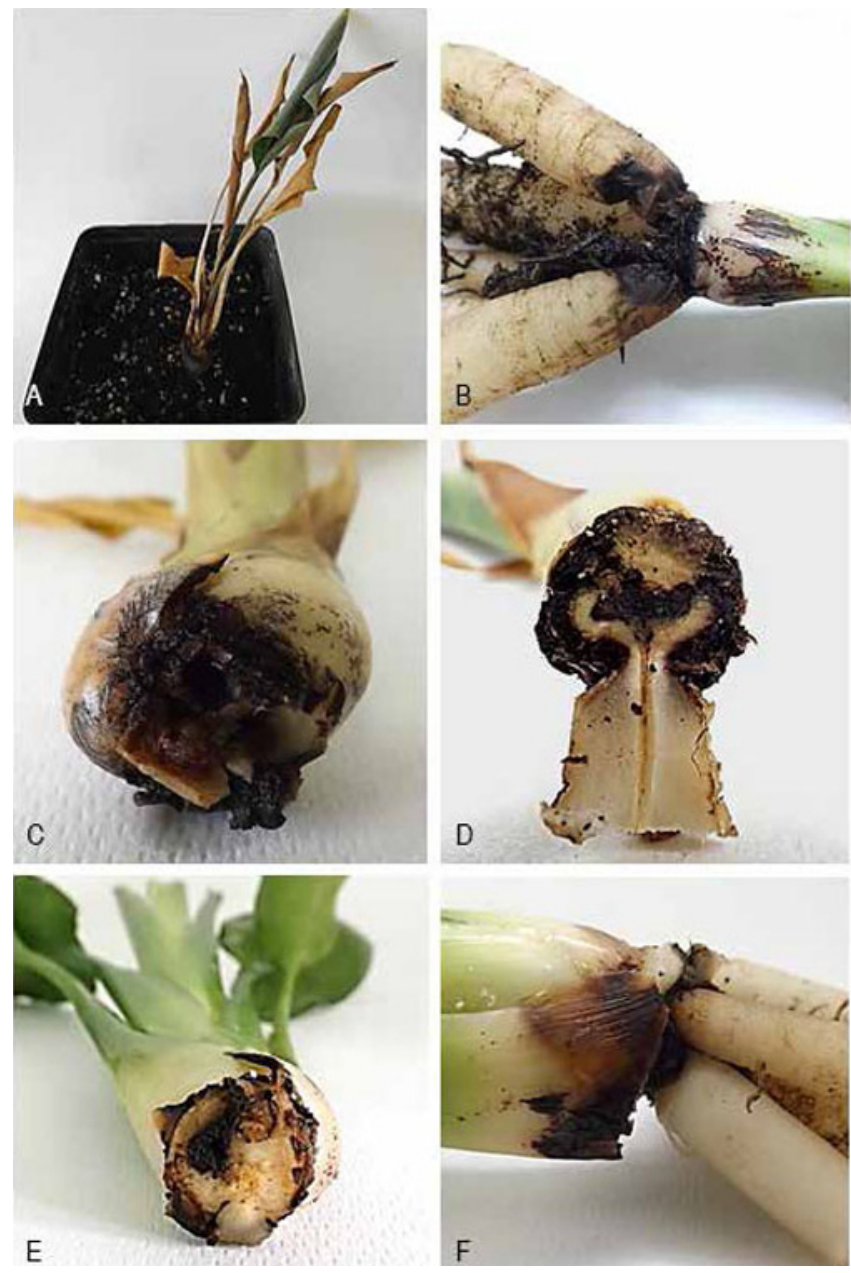

Fig. 3. Symptoms induced during the pathogenicity test on Strelitzia reginae. A-D. Basal rot and wilting of plant caused by Pleiocarpon strelitziae. E-F. Basal stem rot and rot of external leaf caused by Ilyonectria strelitziae.

\section{TAXONOMY}

Morphological observations supported by phylogenetic inference showed that the isolates obtained from the diseased Strelizia reginae included a new taxon in the genus Ilyonectria, and a novel cylindrocarpon-like genus, both of which are described below.

\section{Ilyonectria strelitziae L. Lombard \& D. Aiello, sp. nov. MycoBank MB820027}

(Fig. 4)

Etymology: Name derived from the host, Strelitzia reginae, from which this fungus was isolated.

Diagnosis: Perithecia orange-red with simple conidiophores arising directly from the surface of the ascomatal wall. Asexual morph producing abundant micro- and macroconidia, but no chlamydospores in culture.

Type: Italy: Sicily: Catania Province, Carrubba, Riposto, isolated from Strelitzia reginae, 2015, D. Aiello (CBS H-22967 [dried culture] - holotype; CBS 142253 - ex-type culture).
Description: Perithecia formed homothallically in vitro, solitary or in groups of 2-3, developing directly on the SNA agar surface, ovoid to obpyriform, orange-red, becoming purple-red in $3 \% \mathrm{KOH}$, finely warted, 275-320 $\mu \mathrm{m}$ diam, to $375 \mu \mathrm{m}$ high; with simple conidiophores arising directly from the surface of the ascomatal wall, and without a recognisable stroma; perithecial wall consisting of two poorly distinguishable regions; outer region 8-12 $\mu \mathrm{m}$ thick, composed of 2-4 layers of textura angularis to textura globosa; inner region 3-5 $\mu \mathrm{m}$ thick, composed of 3-4 layers of textura angularis. Asci subcylindrical to clavate, 25-75 $\times$ 4-9 $\mu \mathrm{m}, 8$-spored; apex truncate to bluntly rounded, with a visible ring. Ascospores ellipsoidal, hyaline, tapering towards both ends, divided into two equal sized cells, smooth, (8-)9-11 × 3-4 $\mu \mathrm{m}$. Conidiophores simple, solitary or aggregated into sporodochial-like structures, arising laterally or terminally from aerial mycelium or erect, arising from the agar surface, unbranched or sparsely branched, 1-4-septate, 60-190 $\mu \mathrm{m}$ long, bearing one or rarely two conidiogenous cells. Conidiogenous cells monophialidic, cylindrical, tapering slightly towards the apex, 17-60 long, and 2-4 $\mu \mathrm{m}$ wide at the base; micro- and macroconidia produced by simple conidiophores. Microconidia abundant, aseptate, ellipsoidal to ovoidal or subcylindrical, straight to slightly curved, with a clearly laterally displaced hilum, 5-7(-9) × 2-3 $\mu \mathrm{m}$ (av. 6 $\times 2 \mu \mathrm{m}$ ), formed in heads on conidiophores. Macroconidia 1-3-septate, straight to slightly curved, base sometimes with a visible, centrally located to laterally displaced hilum; 1-septate macroconidia (9-)11-17(-20) $\times 2-4 \mu \mathrm{m}$ (av. $14 \times$ $3 \mu \mathrm{m})$; 2-septate macroconidia (14-)18-22(-24) $\times 3-4 \mu \mathrm{m}$ (av. $20 \times 4 \mu \mathrm{m})$; 3-septate macroconidia (19-)21-29(-37) $\times$ 3-4 $\mu \mathrm{m}$ (av. $25 \times 4 \mu \mathrm{m}$ ). Chlamydospores not observed on SNA or PDA.

Culture characteristics: Colonies after $10 \mathrm{~d}$ at $24^{\circ} \mathrm{C}$ on PDA with cottony, white aerial mycelium in the centre, lacking zonation; centre dark brick becoming cinnamon to honey towards the margins; reverse dark brick in centre, becoming cinnamon towards the margins.

Cardinal growth temperatures: No growth was observed at 4 and $35^{\circ} \mathrm{C}$. Optimal growth was observed at $20^{\circ} \mathrm{C}$, with colonies reaching 265-615 $\mathrm{mm}$ diam.

Additional culture examined: Italy: Sicily: Catania Province, Carrubba, Riposto, isolated from Strelitzia reginae, 2015, D. Aiello (CBS 142254).

Notes: Based on the phylogenetic inference obtained in this study, Ilyonectria palmarum (Aiello et al. 2014) is the closest phylogenetic neighbour to $I$. strelitziae (Fig. 2). Ilyonectria strelitziae can be distinguished from $I$. palmarum by the simple conidiophores arising from the ascomatal wall, a character not previously reported in Ilyonectria (Chaverri et al. 2011, Cabral et al. 2012a, b, Lombard et al. 2013, 2014, 2015). Additionally, I. strelitziae readily produced 1-septate macroconidia, not reported for $I$. palmarum (Aiello et al. 2014). 

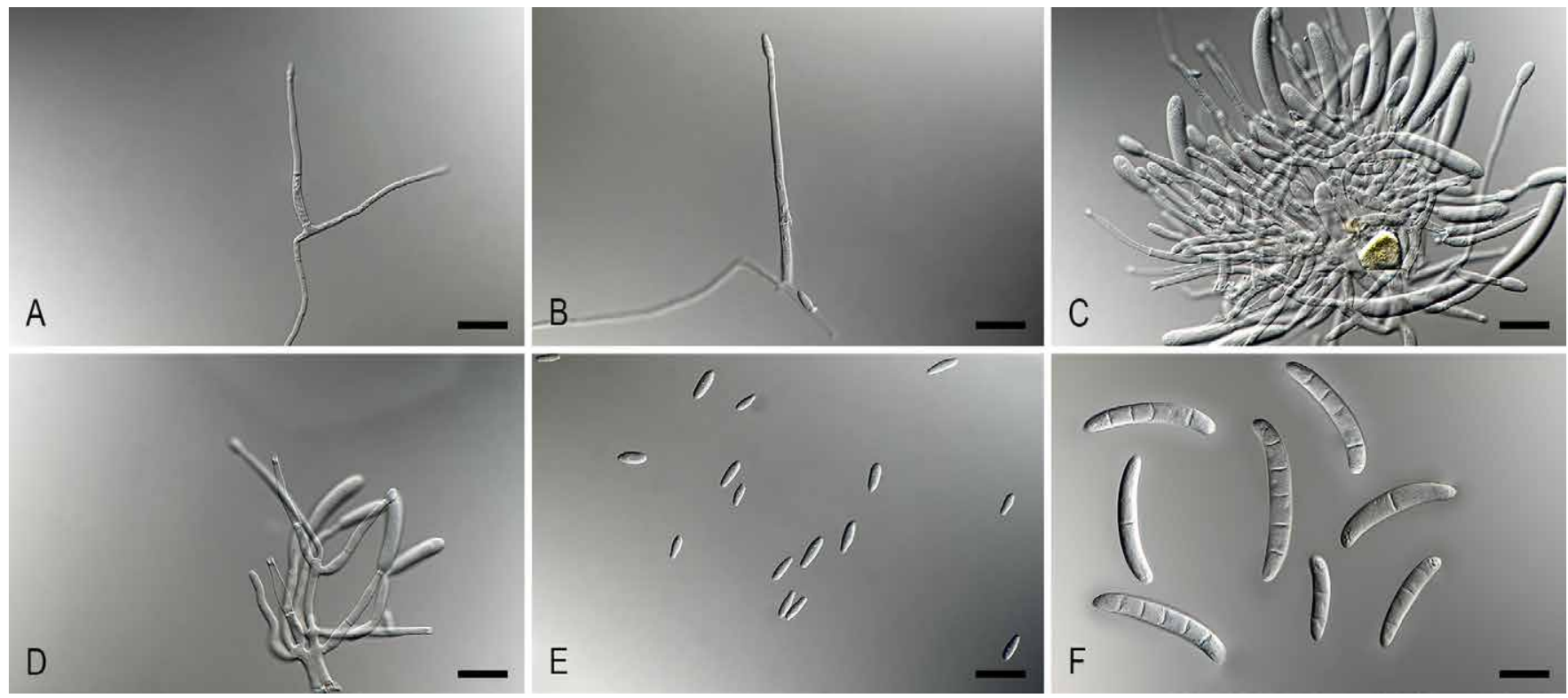

Fig. 5. Pleiocarpon strelitziae (ex-type CBS 142251). A-B. Simple conidiophores. C-D. Sporodochia. E. Microconidia. F. Macroconidia. Bars = $10 \mu \mathrm{m}$

Pleiocarpon L. Lombard \& D. Aiello, gen. nov. MycoBank MB820028

(Fig. 5)

Etymology: Named after the highly variable conidial shapes this fungus produces in culture.

Diagnosis: Sexual morph unknown. Asexual morph cylindrocarpon-like; microconidia abundant, aseptate, ellipsoid to ovoid or subcylindrical, straight to slightly curved, with clearly laterally displaced hilum; macroconidia cylindrical to subcylindrical, straight to curved, 1-5-septate.

Type species: Pleiocarpon strelitziae L. Lombard \& D. Aiello 2017.

Description: Ascomata not observed. Conidiophores simple or aggregated to form sporodochia; simple conidiophores arising laterally or terminally from aerial mycelium, solitary to loosely aggregated, unbranched or sparsely branched, septate, bearing up to two conidiogenous cells. Conidiogenous cells monophialidic, cylindrical, tapering slightly towards the apex. Microconidia abundant, aseptate, hyaline, ellipsoid to ovoid or subcylindrical, straight to slightly curved, with clearly laterally displaced hilum. Macroconidia cylindrical to subcylindrical, hyaline, straight to curved, 1-5-septate, apex or apical cell typically slightly bent to one side and minutely beaked, base with sometimes visible, centrally located or laterally displaced hilum. Chlamydospores not observed.

Notes: Pleiocarpon is a new cylindrocarpon-like monotypic genus, phylogenetically closely related to the genus Thelonectria (Chaverriet al. 2011). The asexual morph of Thelonectria rarely produces microconidia (Chaverri et al. 2012, Salgado-Salazar et al. 2016) in contrast to Pleiocarpon. Additionally, the macroconidia of the asexual morph of Thelonectria are large and up to 9-septate (Chaverri et al. 2012, Salgado-Salazar et al. 2016), whereas those of Pleiocarpon are more intermediate in size and up to 5-septate.

Pleiocarpon strelitziae L. Lombard \& D. Aiello, sp. nov.

MycoBank MB820029

(Fig. 5)

Etymology: Name derived from the host, Strelitzia reginae, from which this fungus was isolated.

Type: Italy: Sicily: Catania Province, Carrubba, Riposto, isolated from Strelitzia reginae, 2015, D. Aiello (CBS H-22967 [dried culture] - holotype; CBS 142251 - ex-type culture).

Description: Ascomata not observed. Conidiophores simple or aggregating to form sporodochia. Simple conidiophores solitary, arising laterally or terminally from aerial mycelium, to loosely aggregated, unbranched or sparsely branched, 1-3-septate, 50-85 $\mu \mathrm{m}$ long, bearing one, rarely two conidiogenous cells. Conidiogenous cells monophialidic, cylindrical, tapering slightly towards the apex, 22-47 $\mu \mathrm{m}$ long, 2-3 $\mu \mathrm{m}$ wide at the base. Sporodochia consisting of a pulvinate mass of short conidiophores, the conidiogenous cells monophialidic, cylindrical, tapering towards the apex, 12-23 $\mu \mathrm{m}$ long, and 2-4 $\mu \mathrm{m}$ wide at the base. Microconidia aseptate, with a minute or clearly laterally displaced hilum, ellipsoid to ovoid or subcylindrical, straight to slightly curved, $(6-) 7-9 \times 2-3 \mu \mathrm{m}$ (av. $8 \times 3 \mu \mathrm{m})$, formed in heads on simple conidiophores or in hyaline, slimy masses on sporodochia. Macroconidia formed by both types of conidiophores, cylindrical to subcylindrical, hyaline, straight to curved, 1-5-septate, apex or apical cell typically slightly bent to one side and minutely beaked, base with sometimes visible, centrally located or laterally displaced hilum; 1-septate macroconidia (19-)27-40 × (3-)5-7 $\mu \mathrm{m}$ (av. $35 \times 6 \mu \mathrm{m})$; 2-septate macroconidia 23-29(-31) $\times 5 \mu \mathrm{m}$ (av. $26 \times 5 \mu \mathrm{m})$; 
3-septate macroconidia (28-)30-40(-46) × 5-6 $\mu \mathrm{m}$ (av. $35 \times$ $6 \mu \mathrm{m}$ ); 4-septate macroconidia (36-)37-41 × 6-7 $\mu \mathrm{m}$ (av. 39 $\times 6 \mu \mathrm{m}) ; 5$-septate macroconidia (41-)42-47(-50) $\times 5-7 \mu \mathrm{m}$ (av. $44 \times 6 \mu \mathrm{m})$. Chlamydospores not observed.

Culture characteristics: Colonies after $10 \mathrm{~d}$ at $24^{\circ} \mathrm{C}$ on PDA with sparse cottony, white aerial mycelium, lacking zonation; surface and reverse cinnamon to honey.

Cardinal growth temperatures: No growth observed at 4 ${ }^{\circ} \mathrm{C}$, while colonies grew at $10-35{ }^{\circ} \mathrm{C}$, with optimal growth at $25-30{ }^{\circ} \mathrm{C}$ with colonies reaching $410-460 \mathrm{~mm}$ diam in one week.

Additional culture examined: Italy: Sicily: Catania Province, Carrubba, Riposto, isolated from Strelitzia reginae, 2015, D. Aiello (CBS 142252).

\section{DISCUSSION}

Basal stem and root rot of Strelitzia reginae can be caused by different fungal species, including Armillaria mellea, Fusarium spp., Phytophthora spp., Pythium spp., Rhizoctonia solani, and Sclerotium rolfsii. In our study, a new dry basal stem rot was detected on potted $S$. reginae plants cultivated in a nursery in eastern Sicily. Three different cylindrocarpon-like species were consistently isolated from diseased plants, while the above-mentioned pathogens were not found associated with the symptomatic tissues.

According to phylogenetic inference supported by morphological characters, some of the isolates associated with this new dry basal rot of $S$. reginae were identified as a new species of llyonectria, described here as I. strelitziae. Species of this genus are commonly found in soil and cause collar and root diseases on a wide range of plant hosts worldwide (Sánchez et al. 2002, Seifert et al. 2003, Halleen et al. 2004, 2006, Alaniz et al. 2007, 2009, Agustí-Brisach et al. 2011, Dart \& Weeda 2011, Petit et al. 2011, Cabral et al. 2012a, b, Özben et al. 2012, Úrbez-Torres et al. 2012, Erper et al. 2013, Lombard et al. 2013, 2014). In Italy, several species have been reported from ornamental nurseries in eastern Sicily. Dactylonectria pauciseptata, I. novozelandica, and $I$. torresensis, were reported on potted Laurus tinus plants associated with root and crown rot symptoms (Aiello et al. 2015); I. palmarum associated with dry basal rot of Arecaceae (Aiello et al. 2014); and I. macrodidyma associated with root rot of avocado (Persea americana; Vitale et al. 2012).

The pathogenicity test in this study showed that $I$. strelitziae induced similar dry basal rot symptoms on $S$. reginae plants to those observed in the nursery. However, nothing is yet known on the origin of this fungal pathogen or its distribution in southern Sicily, which requires further investigation

Some of the remaining isolates obtained from S. reginae also had a cylindrocarpon-like morphology, which phylogenetic inference in this study showed to represent a separate genus, here named Pleiocarpon, based on the new species $P$. strelitziae. Phylogenetic inference showed that these fungi formed a highly-supported, but distinct, clade closely related to the genus Thelonectria. The genus Thelonectria was introduced by Chaverri et al. (2011) to accommodate fungi with cylindrocarpon-like asexual morphs belonging to Booth's Group 2 (Booth 1966), characterized by lacking microconidia and chlamydospores. Recently, Salgado-Salazar et al. (2016) segregated Thelonectria by introducing three new genera (Cinnamomeonectria, Macronectria, and Tumenectria) based on phylogenetic inference. Pleicarpon can be distinguished from these four genera by the abundant microconidia it produces in culture. Moreover, these genera morphologically resemble Thelonectria, and are mostly found on bark or exposed wood of dead, dying or diseased trees, and are rarely associated with small cankers and root rots (Chaverri et al. 2011, Salgado-Salazar et al. 2016). Pathogenicity tests undertaken in this study demonstrated the aggressive pathogenic nature of $P$. strelitziae, resulting in mortality of all inoculated test plants within $2 \mathrm{mo}$, which should be of great concern to the cut-flower industry. However, the origin and distribution of this aggressive pathogen still requires further investigation.

One isolate obtained from diseased $S$. reginae plants was identified as $T$. olida based on phylogenetic inference. However, the morphology could not be confirmed, as the isolate did not sporulate on any of the media used. Past phylogenetic studies (Chaverri et al. 2011, Salgado-Salazar et al. 2016) have shown that this atypical species belongs in the genus Thelonectria, although this species produces chlamydospores and has shorter macroconidia. Thelonectria olida has been isolated from rotting roots of several plant hosts, but its pathogenicity has never been confirmed (Salgado-Salazar et al. 2016). The T. olida isolate obtained was excluded from the pathogenicity test undertaken in this study, as its identity was only determined after these had been carried out.

On the basis of the disease incidence and severity observed in the ornamental nursery, we believe that this disease represents a serious threat to potted field-grown plants of $S$. reginae. The cultivation method of pot production could play an important role in promoting infections, since the plants are stressed by frequently being replanting into pots, and wounds can be incurred during transplanting. Moreover, the use of infected soil could represent a further inoculum source for these fungi (Aiello et al. 2014).

A wilt disease associated with root rot of $S$. reginae caused by Cylindrocarpon destructans was reported in Sicily, but that fungus was identified based only on morphological features (Grasso \& Cutuli 1972) and requires critical confirmation.

To our knowledge, this is the first report worldwide of a dry basal stem rot of $S$. reginae, which in Italy was shown to be caused by two new species, Pleiocarpon strelitziae and Ilyonectria strelitziae.

\section{REFERENCES}

Agustí-Brisach C, Gramaje D, León M, García-Jiménez J, Armengol $J$ (2011) Evaluation of vineyard weeds as potential hosts of blackfoot and Petri disease pathogens. Plant Disease 95: 803-810.

Aiello D, Guarnaccia V, Epifani F, Perrone G, Polizzi G (2015) 'Cylindrocarpon' and llyonectria species causing root and crown 
rot disease of potted Laurustinus plants in Italy. Journal of Phytopathology 163: 675-680.

Aiello D, Guarnaccia V, Vitale A, Cirvilleri G, Granata G, et al. (2014) Ilyonectria palmarum sp. nov. causing dry basal stem rot of Arecaceae. European Journal of Plant Pathology 138: 347-359.

Alaniz S, Armengol J, León M, García-Jiménez J, Abad-Campos $P$ (2009) Analysis of genetic and virulence diversity of Cylindrocapon liriodendri and C. macrodidymum associated with black foot disease of grapevine. Mycological Research 113: 16-23.

Alaniz S, León M, Vincent A, García-Jiménez J, Abad-Campos P, et al. (2007) Characterization of Cylindrocarpon species associated with black foot disease of grapevine in Spain. Plant Disease 91 : 1187-1193.

Alfieri SA Jr, Langdon KR, Wehlburg C, Kimbrough JW (1984) Index of Plant Diseases in Florida (Revised). Florida Department of Agriculture and Consumer Services, Division of Plant Industry Bulletin 11: 1-389.

Booth C (1966). The genus Cylindrocarpon. Mycological Papers 104: $1-54$.

Cabral A, Groenewald JZ, Rego C, Oliveira H, Crous PW (2012a) Cylindrocarpon root rot: multi-gene analysis reveals novel species within the llyonectria radicicola species complex. Mycological Progress 11: 655-688.

Cabral A, Rego C, Nascimento T, Oliveira H, Groenewald JZ, et al. (2012b) Multi-gene analysis and morphology reveal novel Ilyonectria species associated with black foot disease of grapevines. Fungal Biology 116: 62-80.

Chaverri P, Salgado C, Hirooka Y, Rossman AY, Samuels GJ (2011) Delimitation of Neonectria and Cylindrocarpon (Nectriaceae, Hypocreales, Ascomycota) and related genera with Cylindrocarpon-like anamorphs. Studies in Mycology 68: 57-78.

Crous PW, Gams W, Stalpers JA, Robert V, Stegehuis G (2004) MycoBank: an online initiative to launch mycology into the $21^{\text {st }}$ century. Studies in Mycology 50: 19-22.

Dart NL, Weeda SM (2011) First report of Cylindrocarpon macrodidymum on Acer palmatum in Virginia. Plant Disease 95: 1592.

Davino M (1984) Infezioni di Armillaria mellea su piante di Strelitzia. Colture protette 13(4): 63-65.

Erper I, Agustí-Brisach C, Tunali B, Armengol J (2013) Characterization of root rot disease of kiwifruit in the Black Sea region of Turkey. European Journal of Plant Pathology 136: 291-300.

Frisullo F, Babelegoto N, Varvaro L (1987) Danni da Phytophtora nicotianae su Strelitzia reginae in Puglia. La difesa delle Piante 10: 281-288.

Grasso S, Cutuli G (1972) Un deperimento della "Strelitzia reginae" da Cylindrocarpon destructans Rivista di Patologia Vegetale, ser. IV 8: 207-214.

Halleen F, Schroers HJ, Groenewald JZ, Crous PW (2004) Novel species of Cylindrocarpon (Neonectria) and Campylocarpon gen. nov. associated with black foot disease of grapevines (Vitis spp.). Studies in Mycology 50: 431-455.

Halleen F, Schroers HJ, Groenewald JZ, Rego C, Oliveira H, et al. (2006) Neonectria liriodendri sp. nov., the main causal agent of black foot disease of grapevines. Studies in Mycology 55: 227-234.

Hilal AA, Helmy AA (1998) Diseases of bird of paradise (Strelitizia reginae Banks) in Egypt root and flower rots. Egyptian Journal of Agricultural Research 76: 33-49.

Karsten J (2009) Envolvimento da peroxidase e polifenoloxidases no bloqueio xilemático de hastes de ave-do-paraiso (Strelitzia reginae). Dissertaçãoa, universidade Federal de Viçosa (Mestrado em Fisiologia Vegetal), Viçosa, Minas Gerais, Brasil.

Katho K, Standley DM (2013) MAFFT multiple sequence alignment software version 7: improvements in performance and usability. Molecular Biology and Evolution 30: 772-780.

Kumar S, Stecher G, Tamura K (2015) MEGA7: Molecular Evolutionary Genetics Analysis version 7.0 for bigger datasets. Molecular Biology and Evolution 33: 1870-1874.

Lombard L, Bezuidenhout CM, Crous PW (2013) Ilyonectria black foot rot associated with Proteaceae. Australasian Plant Pathology 42: 337-349.

Lombard L, Van der Merwe NA, Groenewald JZ, Crous PW (2014) Lineages in Nectriaceae: re-evaluating the generic status of Ilyonectria and allied genera. Phytopathologia Mediterranea 53: 515-532.

Lombard L, Van der Merwe NA, Groenewald JZ, Crous PW (2015) Generic concepts in Nectriaceae. Studies in Mycology 80: 189-245.

Luongo L, Galli M, Riccioni L, Belisario A (2010) First Report of Leaf Blight and Root and Foot Rot of a Strelitzia Caused by Phytophthora nicotianae in Italy. Plant Disease 94: 134.

Mason-Gamer R, Kellogg E (1996) Testing for phylogenetic conflict among molecular datasets in the tribe Triticeae (Graminae). Systematic Biology 45: 524-545.

Nirenberg HI (1981) A simplified method for identifying Fusarium spp. occurring on wheat. Canadian Journal of Botany 59: 1599-1609.

Nylander JAA (2004) MrModeltest v. 2. Programme distributed by the author. Uppsala: Evolutionary Biology Centre, Uppsala University.

Özben S, Demirci F, Değirmenci K, Uzunok S (2012) First report of Cylindrocarpon macrodidymum associated with black foot disease of grapevine in Turkey. Plant Disease 96: 762.

Petit E, Barriault E, Baumgartner K, Wilcox WF, Rolshausen PE (2011) Cylindrocarpon species associated with black-foot of grapevine in northeastern United States and southeastern Canada. American Journal of Enology and Viticulture 62: 177-183.

Polizzi G, Aiello D, Castello I, Vitale A, Parlavecchio G (2007) First report of southern blight on firewheel tree, bay laurel, bird of paradise, Mediterranean fan palm, and liverwort caused by Sclerotium rolfsii in Italy. Plant Disease 91: 1199.

Raabe RD, Connors IL, Martinez AP (1981) Checklist of Plant Diseases in Hawaii. Honolulu: Hawaii Institute of Agriculture and Human Resources, College of Tropical Agriculture and Human Resources, University of Hawaii.

Rayner RW (1970) A Mycological Colour Chart. Kew: Commonwealth Mycological Institute.

Rego C, Nascimento T, Oliveira H (2001) Characterization of Cylindrocarpon destructans isolates from grapevine in Portugal. Phytopathologia Mediterranea 40: S343-S350.

Ronquist F, Huelsenbeck JP (2003) MrBayes 3: Bayesian phylogenetic inference under mixed models. Bioinformatics 19: 1572-1574.

Salgado-Salazar C, Rossman AY, Chaverri P (2013) Not as ubiquitous as we thought: taxonomic crypsis, hidden diversity and cryptic speciation in the cosmopolitan fungus Thelonectria discophora (Nectriaceae, Hypocreales, Ascomycota). PLoS One 8(10): e76737.

Salgado-Salazar C, Rossman AY, Chaverri P (2016) The genus Thelonectria (Nectriaceae, Hypocreales, Ascomycota) and 
closely related species with cylindrocarpon-like asexual morphs. Fungal Diversity 80: 411-455.

Sánchez ME, Lora F, Trapero A (2002). First report of Cylindrocarpon destructans as a root pathogen of Mediterranean Quercus species in Spain. Plant Disease 86: 693.

Seifert KA, McMullen CR, Yee D, Reeleder RD, Dobinson KF (2003) Molecular differentiation and detection of ginseng-adapted isolates of the root rot fungus Cylindrocarpon destructans. Phytopathology 93: 1533-1542.

Stamatakis A (2014) RAxML Version 8: A tool for phylogenetic analysis and post-analysis of large phylogenies. Bioinformatics 30: 1312-1313.

Swofford DL (2003) PAUP*: phylogenetic analysis using parsimony ( ${ }^{*}$ and other methods). Version 4.0b10. Sunderland, MA: Sinauer Associates,
Úrbez-Torres JR, Peduto F, Gubler WD (2012) First report of Ilyonectria macrodidyma causing root rot of olive trees (Olea europaea) in California. Plant Disease 96: 1378.

Van Jaarsveld E (2008) Strelitzia reginae Banks ex Aiton. subsp. Mzimvubuensis Van Jaarsv. http://www.plantzafrica.com/plantqrs/ strelitzregmzimvu.htm.

Vitale A, Aiello D, Guarnaccia V, Perrone G, Stea G, et al. (2012) First outbreak of root rot caused by Neonectria (Ilyonectria) macrodidyma on avocado (Persea americana). European Journal of Phytopathology 160: 156-159.

Xaba P (2011) Strelitzia reginae Aiton. http://www.plantzafrica.com/ plantqrs/strelitziareginae.htm. 